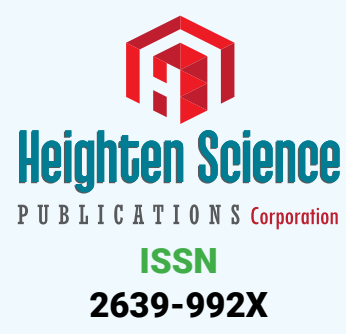

*Address for Correspondence: Carlos Alberto Kelencz, UniRadial Estácio University Center, Interlagos, São Paulo, Brazil, Email: carloskelencz@terra.com.br

Submitted: 21 December 2016

Approved: 23 January 2017

Published: 24 January 2017

Copyright: @ 2017 Kelencz CA, et al. This is an open access article distributed under the Creative Commons Attribution License, which permits unrestricted use, distribution, and reproduction in any medium, provided the original work is properly cited

Keywords: Electromyography; EMG; Human gait; Footwear

Check for updates
Research Article

\section{Kinematics and Electromyographic Analysis of Gait with Different Footwear}

\author{
Carlos Alberto Kelencz ${ }^{1,5 *}$, Ingrid Solange Sepúlveda Muñoz ${ }^{2}$, \\ Paulo Rui de Oliveira ${ }^{4}$, Bruno Mazziotti ${ }^{3,4}$ and Cesar Ferreira \\ Amorim 4 \\ 'UniRadial Estácio University Center, Interlagos, São Paulo, Brazil \\ ${ }^{2}$ Fcavest University Center, Santa Catarina, Brazil \\ ${ }^{3}$ Shandong Luneng Taishan Football Club, Jinan, Shandong, China \\ ${ }^{4}$ Master and Doctoral Program in Physical Therapy-University of City of São Paulo, UNICID, \\ Brazil \\ ${ }^{5}$ Centro Universitário Ítalo Brasileiro, São Paulo, Brazil
}

\section{ABSTRACT}

Kinematic analysis and surface electromyography are tools being used as important methods to evaluate the human gait and to analyze different types of footwear aiming modifications and adaptations to the human locomotor system, especially of the feet. The aim of the present study was to analyze through electromyography (EMG) the muscles tibialis anterior (TA) and gastrocnemius lateralis (GL) and gastrocnemius medialis $(G M)$ and to capture digital images of the human gait in four different footware situations, barefoot with tennis, platform shoes and high heels. Twenty healthy women with a mean age of 22.6 years took part in this experiment, which was performed on a treadmill at a speed of $3.8 \mathrm{~m} / \mathrm{s}$. The results showed that shoes that do not allow a normal movement of the tarsal bones caused changes in the trajectory of the gait, which promotes a greater muscular movement. This study concluded that shoes closer to a normal position and allow greater mobility of the feet, decrease muscular demands, which in everyday situations cause less localized muscular fatigue.

\section{INTRODUCTION}

Walking or ambulation is the most common movement in human beings. The standard footstep variability in everyday life is moderately low [1]. The analysis of human movement is defined as any procedure involving means that allow obtaining its quantitative or qualitative measure [2]. The gait cycle is a perfectly orchestrated sequence of electrical and mechanical events that culminates in the coordinated propulsion of the body through space. This cycle should be seen as a coordinated effort between the nervous, the muscular, and the skeletal systems [3,4]. Any disturbance in the motor, musculoskeletal, or sensory systems can cause weakness in locomotion. The term gait analysis has become common when describing the evaluation modes of locomotion, which take into account anthropometric, kinematic, kinetic or Electromyographic aspects $[5,6]$. Some external factors can also significantly affect the way of locomotion, such as the walking surface or the type of footwear. Brazil in 2002 became the first country to create norms that evaluate the comfort of footwear, NBR 14834 to 14840 [7].

There are numerous measurement procedures which analyze the gait and are related, in a greater or lesser degree, to the control of this movement. The EMG signal 
measures moments of force and power closely measure the origin of movement, whereas kinematics moments, support, footstep length, cadence, and ground reaction forces merely reflect many integrated output effects [1]. The use of video cameras, force platforms and electromyography (EMG) in order to characterize locomotion quantitatively has become increasingly frequent, becoming a common system to evaluating changes in the gait $[8,9]$. The use of video cameras allows greater flexibility in the selection of the movements to be studied, the acquisition frequency of $60 \mathrm{~Hz}$ provides a sufficient temporal resolution for a large number of biomechanical analysis $[10,5]$. The analysis of the gait now counts on the evolution of measurement methods and techniques provided by the technological advance which allows the access to different behaviours of the locomotive system in a more precise and quicker way [11]. In this sense, the aim of this work is to perform a kinematic study of the feet and an electromyography study of the tibialis anterior, lateral gastrocnemius and medial gastrocnemius muscles on the treadmill, in four different situations: barefoot, with tennis, with platform shoes and high heels.

\section{METHODOLOGY}

Twenty women aged \pm 22.66 , \pm weight $56.22 \mathrm{~kg}$ and height \pm 163.35 , with similar anthropometry and no history of musculoskeletal injuries, took part in this experiment. To capture the images, we used a Sony Cyber shot digital still camera with a 10.1 megapixel resolution. It was attached to a tripod positioned fifty centimetres from the ground, one meter from the volunteer. Silver markers were positioned at ankle joint, tip of the foot and heel levels for better visualization of the reference points. For the Electromyographic records, a 16-channel electromyography model SAS1000-V16 version EMG800C-16 and a specific software EMG Lab 1.2 by EMG System do Brasil for the data analysis, and surface electrodes coupled to the active interface were used. They were positioned on the tibialis anterior (TA), lateral gastrocnemius (GL) and medial gastrocnemius (GM) muscles on both sides following the [12,13]. Before the electrodes were placed, a tricotomy and alcohol cleansing were performed on the area of the muscles tested.

To synchronize the Electromyographic records with the filming, a device was used in the form of flash to the trigger the recording [14]. It was fixed on the lateral platform of the treadmill. A Kistler treadmill with at a speed of $3.8 \mathrm{~m} / \mathrm{s}$ was used. All procedures were performed at the Biodynamic Laboratory of the Physiotherapy College of University of Vale do Paraíba. After data acquisition, the image files were transformed into a sequence of images in the VirtualDub-1.7.0 software, and saved in a specific file for further processing in Image $1.38 \mathrm{~b}$, where the Manual Tracking features were used. Specifically, the trajectory of the tip-toe movement of the volunteers, where silver markers had been placed, was observed. A cycle of steps was analyzed and synchronized with the electromyographic signal of the muscles tested. The shoes used in the experiment were: sneakers with non-cushioned rubber soles with a height of $2 \mathrm{~cm}$. Female boot with rubber outsole without cushioning height of $6 \mathrm{~cm}$. And the footwear with needle-like jump with rigid soles with height of $10 \mathrm{~cm}$.

\section{RESULTS}

A tracing was done on the images obtained from the trajectory of the feet during the footstep. This procedure was carried out both on the right and left footstep, and with all the different footwear.

The tracing of the feet's trajectory during the walk without footwear- barefoot (Figure 1) with the right leg was observed. It showed an almost linear trajectory from the initial moment until total foot support on the platform. In chart 1, we observe the electromyographic activity that was synchronized with the image of the mentioned trajectory, in which there was a greater electrical activity of all muscles on the right side compared to the left side. The greatest electrical activity was recorded in the right 


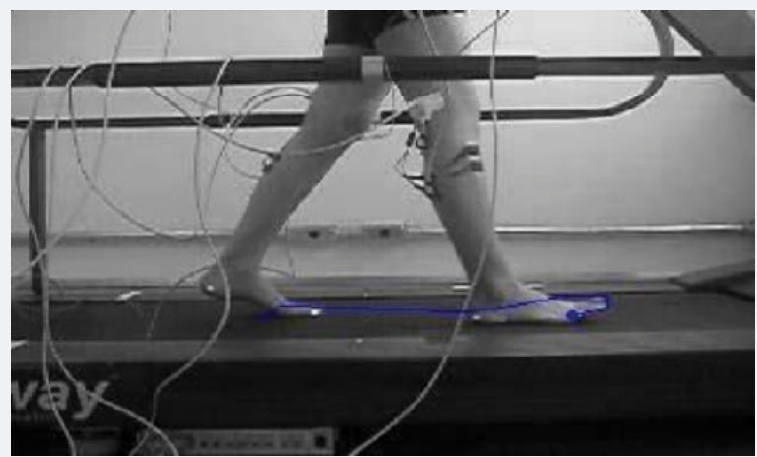

Figure 1: Walking barefoot- The blue line represents the trajectory covered by the right leg during the footstep.

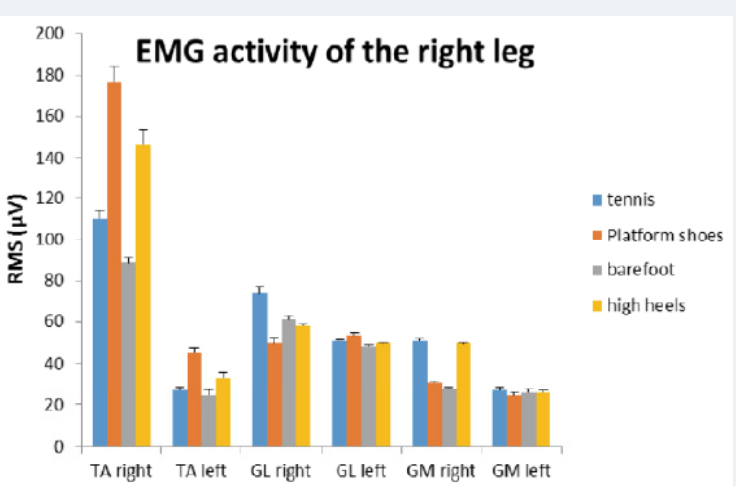

Chart 1: Comparison of the mean EMG activity of all the muscles during the right leg footstep with different footwear, values expressed in Root Mean Square (RMS).

tibialis anterior muscle whose function is the dorsal flexion of the ankle, but which also cushions the impact with the ground.

The left-leg tracing without the use of footwear when compared to the right was more linear, it also covered a smaller distance when the space covered by the feet during the footstep was observed.

The gait of the right leg during the footstep with the use of tennis (Figure 2). It was observed that the foot trajectory was much more sinuous than the previous one and that at the end of the footstep there was an elevation of the foot tip before touching the ground.

Regarding the electrical activity of the muscles, the dominance of all muscles of the right side is observed, and the anterior tibialis was also the most active. Compared to the same side in the previous situation, a significant increase in the electrical activity of this muscle was noticed. This is explained by the modification in the trajectory of the footstep and a greater dorsal flexion of the ankle. The left side presented electrical activity similar to what was observed in the previous situation. The footstep trajectory was similar to that of the left leg but also with a slightly smaller distance than the right leg. When comparing the tracing of electrical activity results of the right leg muscles with another tracing data obtained from an image of walking using tennis, which represent the trajectory traversed by the left leg during the footstep, the gait with the platform shoes as observed in the figure 3, shows a positive slope footstep, showing that with this type of footwear the volunteers raised their feet higher from the ground.

This elevation generates a greater electrical activity of the anterior tibialis muscle of the right leg in relation to the other muscles tested. The same happened in the left leg during the footstep walk with platform shoes. The last situation tested the gait using high heels, as observed in figure 4 . 


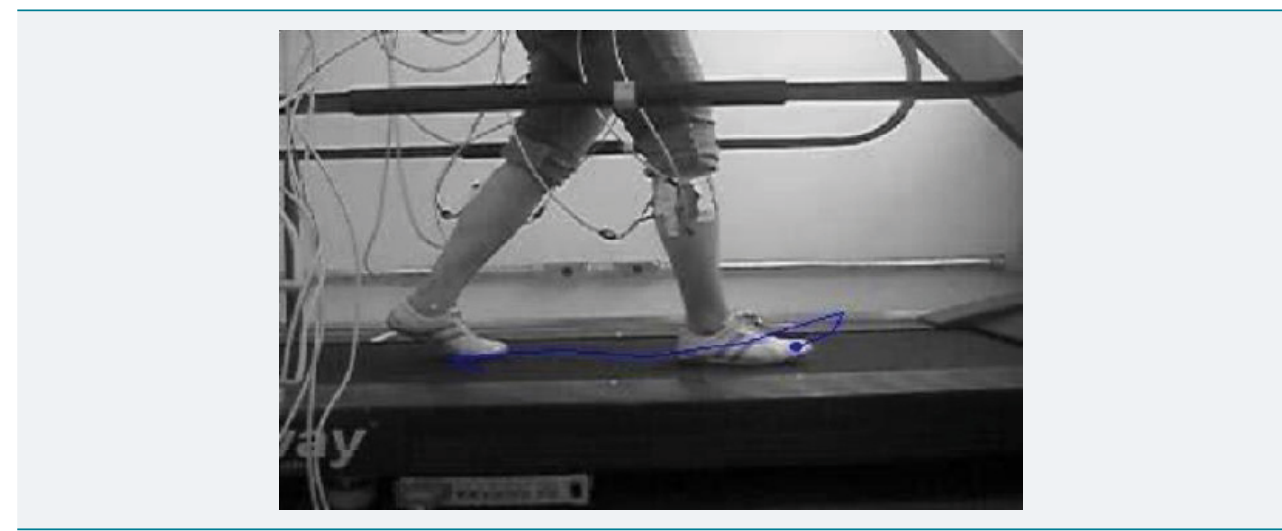

Figure 2: Walking with tennis- The blue line represents the trajectory covered by the right leg during the footstep.

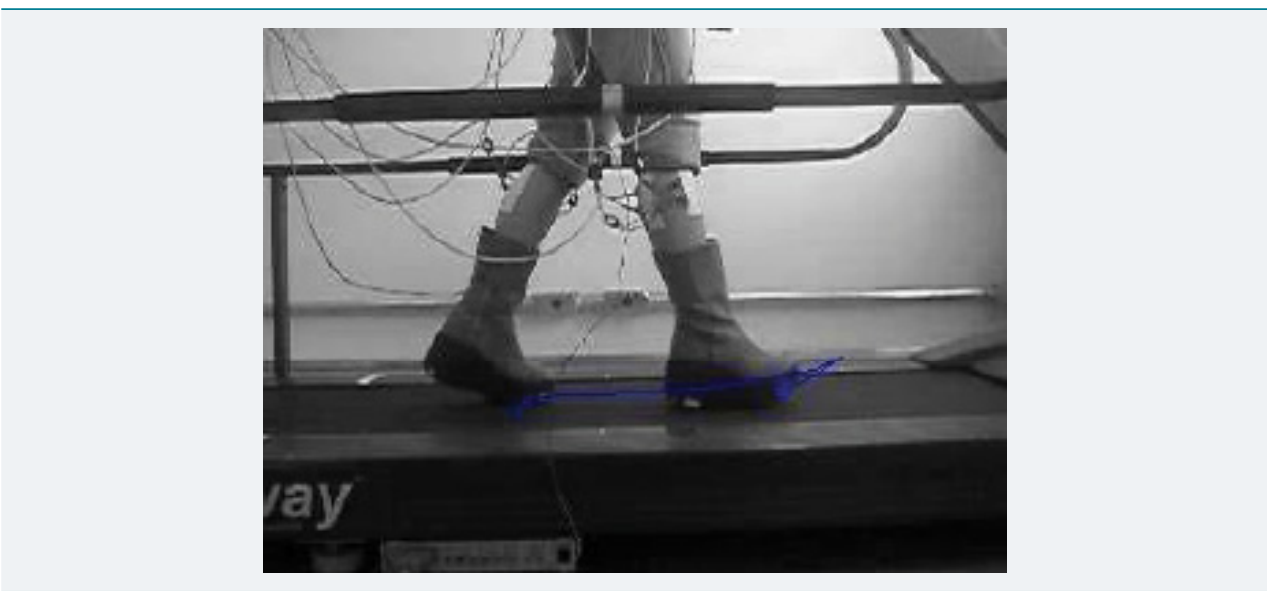

Figure 3: Walking with platform shoes- The blue line represents the trajectory covered by the right leg during the footstep.

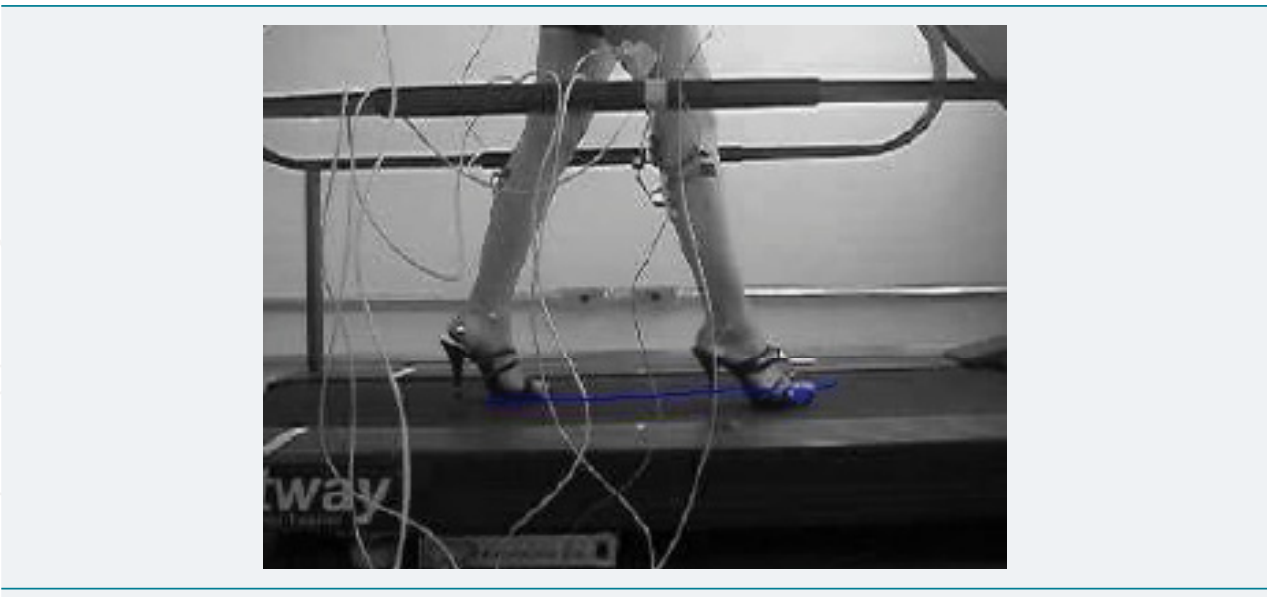

Figure 4: The blue line represents the trajectory covered by the right leg during the footstep on high heels.

A more linear trajectory of the right leg similar to that observed in the data obtained in the results of the electrical activity of the muscles during the footstep of the right leg without footwear (Figure 1), with a shorter distance between the steps, and the almost simultaneous touching of the heel and forefoot.

As in the other situations, the anterior tibialis muscle was more active than the electrical activity of the muscles of the right leg. A similar situation was observed in the gait with platform shoes, of the left leg.

Comparing all the situations tested, it was observed that the platform footwear 
presents a very different foot trajectory than the other footwear, and resulted in a greater electrical activity of the anterior tibialis muscle as observed in charts 1 and 2 .

\section{DISCUSSION}

The results showed that the change in the trajectory of the step, directly reflects on the electric activity of the muscles tested. This is due to the modification in the biomechanics of the feet imposed by the type of footwear which in the case of platform shoes practically does not allow any movement of the bones of the tarsus [15], (Table 1). This leads to an adaptation in the movement of the feet that generates a greater force to perform the movement since the foot support on the ground occurs almost simultaneously at the ankle plant and the tip of the foot $[16,17]$.

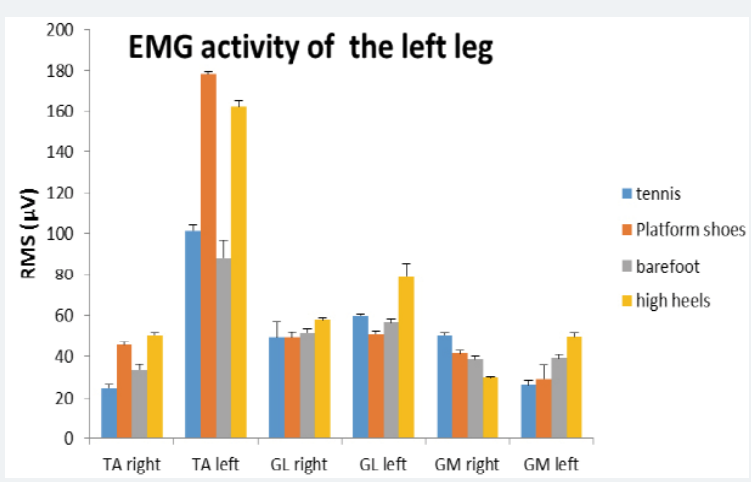

Chart 2: Comparison of the mean EMG activity of all the muscles during the left leg footstep with different footwear, values expressed in Root Mean Square (RMS)

Table 1: Average of evaluated muscles expressed as mean RMS (Root Mean Square) and standard deviation (SD) of Tibialis Anterior (TA), Gastrocnemius Lateralis (GL) and Gastrocnemius Medialis (GM).

\begin{tabular}{|c|c|c|c|c|c|}
\hline \multirow{2}{*}{ Side of leg } & Muscles & $\begin{array}{c}\text { Tennis RMS } \\
(\mu \mathrm{V}),(\mathbf{S D})\end{array}$ & $\begin{array}{c}\text { Platform shoes } \\
\text { RMS }(\boldsymbol{\mu V}),(\mathrm{SD})\end{array}$ & $\begin{array}{c}\text { Barefoot RMS } \\
(\boldsymbol{\mu V}),(\mathrm{SD})\end{array}$ & $\begin{array}{c}\text { High heels RMS } \\
(\boldsymbol{\mu V}),(\mathrm{SD})\end{array}$ \\
\hline \multirow{3}{*}{ Right side } & Tibialis Anterior (TA) & $110.0(3.70)$ & $177.0(7.54)$ & $88.60(2.70)$ & $146.80(6.64)$ \\
\cline { 2 - 6 } & Gastrocnemius Lateralis (GL) & $74.20(2.77)$ & $49.60(2.70)$ & $61.10(1.58)$ & $58.75(0.70)$ \\
\cline { 2 - 6 } & Gastrocnemius Medialis (GM) & $50.82(0.83)$ & $31.84(0.79)$ & $27.86(0.79)$ & $49.65(0.54)$ \\
\hline \multirow{2}{*}{ Left side } & Tibialis Anterior (TA) & $27.20(1.58)$ & $45.43(2.07)$ & $25.19(2.54)$ & $33.23(2.86)$ \\
\cline { 2 - 6 } & Gastrocnemius Lateralis (GL) & $50.75(0.83)$ & $53.40(1.14)$ & $48.10(1.17)$ & $49.64(0.54)$ \\
\cline { 2 - 6 } & Gastrocnemius Medialis (GM) & $27.43(1.58)$ & $24.81(1.30)$ & $25.80(1.92)$ & $26.19(0.70)$ \\
\hline
\end{tabular}

When walking with shoes that allow the feet to move, the step cycle becomes lighter, and all phases of the last cycle are executed. With footwear such as platform shoes and high heels, the feet remain in a fixed position, obliging the locomotor system to make various adjustments and biomechanical adaptations so that the person can move in an unfavourable and uncomfortable position. Comparing all the situations, we observed with the help of digital images and electromyography that the platform shoes presented the greatest difference in muscle activity and foot trajectories [18].

\section{CONCLUSION}

We conclude in this study that the closer to a normal position the shoes are, in other words, the greater the mobility of the feet, the smaller the muscular demands. Which will cause less localized muscle fatigue in day-to-day situations. Regarding the use of digital images in gait analysis with different footwear, we conclude that it is a very important tool and that when synchronized with other biomechanical tools it can bring many benefits to the movement analysis. 


\section{REFERENCES}

1. Winter DA. The biomechanics and motor control of human gait: normal, elderly and pathologiacal. Ontário. University of Waterloo Press. 1991. Ref.: https://goo.gl/NGpRFu

2. Díaz CA, Torres A, Ramírez Jl, García LF, Álvarez N. Descripción De un Dispositivo Destinado al análisis de la marcha en dos Dimensiones, cineMED. Escuela de Ingeniería de Antioquia. 2006; 5: 85-92. Ref.: https://goo.gl/gecED8

3. Lieber RL. Skeletal muscle structure and funtion. Blatimore, Williams \& Wilkins (1992).

4. Teixeira CE, Retondar JJ. The use of high heel by young women: the biomechanic of movement and the imaginary of elegance. Rev Corpus Scient. 2011; 7: 38-54.

5. Araújo CC, Preis C, Ribas D, Romanovitch I, Faller L, et al. "Sistemas de Avaliação da Marcha Humana" Mestrandos do Programa de Pós-Graduação em Tecnologia em Saúde. Pontifícia Universidade Católica do Paraná. 2006.

6. Winter DA. Biomechanics and motor control of human movement. New York: 2005

7. ABNT. Normas Técnicas NBR 14834a 14840, Ed. ABNT, 2002.

8. Okaia LA, Moraes JCT. "Avaliação Funcional de um Sistema para Análise de Movimento". Anais VIII Congresso Brasileiro de Biomecânica. 1999; 339-344.

9. Campos, Alessandra Oliveira, Hutten, Patrícia, Freitas et al. Análise das alterações biomecânicas da força de reação do solo durante adaptação da marcha em esteira. Revista Brasileira de Biomecânica. 2002; 3: 13-9. Ref.: https://goo.gl/x7iCz2

10. Paterniani PE, Sbrenzikofer R, Lima EC, Lago O, Barros RML. "Desenvolvimento de uma metodologia para reconstrução Tridimensional e Análise de superfícies do Corpo Humano". VIII Congresso Brasileiro de Biomecânica. 1999; 299-303.

11. David AC. Aspectos Biomecânicos da Locomoção Infantil. IX Congresso Brasileiro de Biomecânica. $2001 ; 20-24$.

12. Delagi EF, Peortto AO, lazzetti J, Morrison D. Anotomical guide for the electromyography. 2004.

13. Seniam. Surface Electromyography for the Non-invasive Assessment of Muscles. SENIAM project. 2008.

14. Amorim CF, Giannasi LC, Ferreira LM, Magini M, Oliveira CS, et al. Behavior analysis of electromyographic activity of the masseter muscle in sleep bruxers. J Body Mov Ther. 2010; 14 234-238. Ref.: https://goo.gl/r1jbqN

15. De Oliveira Pezzan PA, João SMA, Ribeiro AP, Manfio EF. Postural assessment of lumbar lordosis and pelvic alignment angles in adolescent users and nonusers of high-heeled shoes. J Manipulative Physiol Ther. 2011; 34: 614-21. Ref.: https://goo.gl/Rtxwbz

16. Wang YT, Pascoe DD, Kim CK, Xu D. Forces patterns of heel strike and toe off on different heel heights in normal walking. Foot Ankle Int. 2001; 22: 486-492. Ref.: https://tinyurl.com/y4fd3fuy

17. Gefen A, Megido-Ravid M, Itzchak Y, Arcan M. Analysis of muscular fatigue and foot stability during high-heeled gait. Gait Posture. 2002; 15: 56-63. Ref.: https://goo.gl/PfsOXa

18. Pezzan PA, Sacco IC, João SM. Foot posture and classification of the plantar arch among adolescent wearers and non-wearers of high-heeled shoes. Rev Bras Fisioter. 2009; 13: 398-404. Ref.: https://goo.gl/FCpRjk

19. De Luca CJ. The Use of Surface Electromyography in Biomechanics. JAB. 1997; 13: 135-163. Ref.: https://goo.gl/DAFwvv

20. Basmajian JV, De Luca CJ. Muscle alive: their function revealed by electromyography. Baltimore: Williams and Wilkins. 1985.

21. Disponível em. Ref.: www.seniam.org 